\title{
Avaliação da resposta imune humoral frente a antígenos de Strongyloides venezuelensis
}

\author{
Evaluation of the humoral immune response to \\ Strongyloides venezuelensis antigens
}

\author{
Carla Rodrigues Rigo ${ }^{1,2}$, Susana Zevallos Lescano ${ }^{2,3}$, Cláudia Regina de Marchi ${ }^{2}$ \\ e Vicente Amato Neto ${ }^{2}$
}

\begin{abstract}
RESUMO
A estrongiloidíase afeta 30 milhões de pessoas em 70 países. Usualmente, o diagnóstico dessa enteroparasitose é realizado por testes parasitológicos baseados no hidro termotropismo das larvas eliminadas nas fezes, porém esses têm se mostrado pouco sensíveis. Neste trabalho, extratos antigênicos foram testados pelas técnicas de ELISA, Immunoblotting e IFI, utilizando larvas filarióides de Strongyloides venezuelensis, parasita de roedores, que mostram reação cruzada com epítopos de Strongyloides stercoralis. Sensibilidade de 89, 85, 57\% para a reação de ELISA e de 100, 100 e 96\%, para o Immunoblotting com os antígenos SAL, ZWIP e ZW, e especificidade de 90, 60 e 81\% para o ELISA e 96, 92 e 91\% para o Immunoblotting para os mesmos antígenos, foram encontradas nestes ensaios.
\end{abstract}

Palavras-chaves: Strongyloides venezuelensis. ELISA. Immunoblotting.

\begin{abstract}
Strongyloidiasis affects 30 million people in 70 countries. This enteral parasitosis is usually diagnosed using parasitological tests based on hydrotropism or thermotropism of larvae eliminated in feces, but these tests have been shown to have low sensitivity. In this study, antigenic extracts were tested by means of ELISA, immunoblotting and IFI, using filariform larvae of Strongyloides venezuelensis, a parasite of rodents that shows cross-reactions with Strongyloides stercoralis epitopes. Sensitivity of 89, 85 and 57\% for the ELISA reaction and 100, 100 and 96\% for immunoblotting with the SAL, ZWIP and ZW antigens, and specificity of 90, 60 and $81 \%$ for ELISA and 96, 92 and 91\% for immunoblotting with the same antigens, were found in these assays.
\end{abstract}

Key-words: Strongyloides venezuelensis. ELISA. Immunoblotting.

Apesar da prevalência dos distúrbios gastrointestinais causados pelo Strongyloides stercoralis ser rara, em áreas urbanas e bem desenvolvidas, esses são importantes no Brasil, onde a ocorrência dessa parasitose é favorecida pelo clima tropical do país e pelas baixas condições sociais e sanitárias presentes, ainda hoje, em várias regiões. A estrongiloidíase disseminada, rara entre a população de imunocompetentes, é muito importante em indivíduos imunodeprimidos; ela é decorrente da capacidade de auto-infecção do Strongyloides stercoralis e caracterizada pelo encontro de larvas em múltiplos órgãos, incluindo o sistema nervoso central ${ }^{13} 14151819$.

Os métodos parasitológicos, normalmente empregados para o diagnóstico, baseados no hidro e termotropismo das larvas, são de baixa sensibilidade, devido à pouca eliminação de larvas nas fezes e a seu caráter intermitente. Essa infecção, também, pode ser diagnosticada pela cultura de fezes, mas o tempo demorado (maior do que cinco dias) para liberação do resultado o torna inadequado para os casos de estrongiloidíase disseminada, quando o diagnóstico rápido se faz necessário ${ }^{13} 18$. Além disso, a diferenciação morfológica entre larvas de Strongyloides e as de ancilostomídeos exige técnicos experientes. 0 aperfeiçoamento dos métodos para diagnóstico sorológico representa um avanço na determinação da infecção em populações de risco como: crianças, gestantes, imunossuprimidos; e nos casos de infecções leves, possibilitando a indicação do tratamento específico ${ }^{38}$ aumentando e melhorando assim a sobrevida de pacientes acometidos pela estrongiloidíase disseminada. Uma importante vantagem dos testes imunodiagnósticos, em relação aos parasitológicos, é que eles não dependem do nível de excreção larval ${ }^{15}$.

Uma das principais limitações em se desenvolver testes sorológicos mais sensíveis e específicos é a dificuldade em obter quantidades suficientes de antígenos, que permitam seu

\footnotetext{
1. Bolsista de Mestrado da Fundação de Amparo à Pesquisa do Estado de São Paulo, São Paulo, SP. 2. Laboratório de Investigação Médica, Parasitologia, Instituto de Medicina Tropical, Universidade de São Paulo, São Paulo, SP. 3. Laboratório de Imunopatologia da Esquistossomose, Instituto de Medicina Tropical, Universidade de São Paulo, São Paulo, SP. Endereço para correspondência: Dr. Vicente Amato Neto. Dept ${ }^{\circ}$ de Parasitologia/IMT/USP/LIM 46. Av. Dr. Enéas de Carvalho Aguiar 500/1 andar/sala 20, 05403-000 São Paulo, SP. e-mail: amatonet@usp.br Recebido para publicação em 01/06/2007 Aceito em 25/11/2008
} 
posterior fracionamento e análise $\mathrm{e}^{16}$. Pesquisas experimentais têm sido realizadas visando aumentar a obtenção de antígenos. Estudos já comprovaram que espécies de Strongyloides infectantes em roedores como Strongyloides venezuelensis possuem determinantes antigênicos que apresentam reação cruzada com os antígenos de Strongyloides stercoralis, o que permite utilizá-los para diagnosticar a estrongiloidíase humana ${ }^{20}$. Este trabalho teve como objetivos principais: padronizar um teste de imunofluorescência indireta (IFI) e Enzyme linked immunosorbent assay (ELISA) para o diagnóstico da estrongiloidíase humana utilizando como antígeno larvas filarióides de Strongyloides venezuelensis; purificar o extrato antigênico de larvas filarióides de Strongyloides venezuelensis em coluna de octyl-sepharose; caracterização imunoquímica dos extratos antigênicos obtidos; determinar a sensibilidade e especificidade dos testes de IFI, ELISA, Immunoblotting padronizados para o diagnóstico da estrongiloidíase humana.

\section{MATERIAL E MÉTODOS}

Amostras analisadas. Foram colhidas 241 amostras fecais e sanguíneas de: pacientes do Ambulatório Geral e Didático do Hospital das Clínicas, SP; crianças - Jardim FEPASA, Jundiaí/SP; e também 19 amostras de soro, reagentes com antígenos de Strongyloides provenientes do Laboratório de Parasitologia da Universidade Federal de Uberlândia (UFU), Uberlândia/SP.

Métodos parasitológicos utilizados para triagem. Método de Rugai ${ }^{17}$; método de Hoffman, Pons e Janer'; método de Faust'. Estes métodos foram aplicados em três amostras por paciente, as quais tinham sido colhidas em dias alternados.

Painéis analisados. Após a triagem e exame parasitológico das fezes, os soros dos pacientes foram agrupados em: painel de soros positivos $\left(\mathrm{n}^{0}=25\right)$; painel de soros negativos $\left(\mathrm{n}^{\mathrm{o}}=73\right)$; painel de soros heterólogos $\left(\mathrm{n}^{\mathrm{o}}=61\right)$; painel de Infecções associadas $\left(\mathrm{n}^{\mathrm{0}}=22\right)$ isto é pacientes com outras parasitoses que não estrongiloidíase; painel de Infecções concomitantes $\left(\mathrm{n}^{\mathrm{0}}=3\right)$, pacientes infectados com Strongyloides e outros parasitas.

Obtenção de extratos antigênicos. 1. Reação de imunofluorescência indireta: antígeno em suspensão: larvas filarióides inteiras foram fixadas em formalina $10 \%$, em uma proporção de 1.000 larvas $/ \mathrm{mL}$. Aproximadamente, $3 \mu \mathrm{L}$ dessa suspensão foram pipetados em lâminas comerciais para imunofluorescência, 12 poços/lâmina, secas em estufa a $37^{\circ} \mathrm{C}$ por 30 minutos; antígeno para cortes em crio-micrótomo: larvas filarióides foram fixadas em formalina $4 \%$ e glutaraldeído $1 \%$, em seguida embebidas em Tissue Tek, a inclusão foi feita em tubos eppendorf e congeladas em nitrogênio líquido, os blocos foram, então, cortados com o crio-micrótomo em seções de $4 \mu \mathrm{m}$ de espessura, essas fixadas em lâminas previamente limpas. 2. Ensaio imunoenzimático e reação de immunoblotting: extrato salino de larvas filarióides (SAL): aproximadamente 10.000 larvas foram trituradas em homogeneizador manual de tecidos, até que larvas inteiras não pudessem ser visualizadas em lupa, sendo em seguida o homogenato ressuspendido em $7 \mathrm{~mL}$ solução salina $0,8 \%$ contendo inibidor de protease, Phenylmethyl-sulfonyl Fluoride (PMSF), na concentração de $1 \mathrm{mM} / \mathrm{mL}$. 0 extrato antigênico foi então submetido a 30 ciclos de sonicação a $50 \mathrm{KHz}$, todo o procedimento foi realizado em banho de gelo, e posterior centrifugação a $10.000 \mathrm{~g}$ durante 45 minutos a $4^{\circ} \mathrm{C} .0$ sobrenadante foi cuidadosamente removido, submetido a quantificação do conteúdo protéico, aliquotado e armazenado a $-20^{\circ} \mathrm{C}$; extrato de larvas filarióides em Zwittergent ${ }^{\circledR}$ com e sem inibidores de proteases (ZWIP) e (ZW): larvas ( $100 \mathrm{mg}$, peso úmido) foram ressuspensas em $1,5 \mathrm{~mL}$ de PBS. Após adição de $100 \mu \mathrm{L}$ de Zwittergent ${ }^{\circledR}$ a $10 \%$, a mistura foi homogeneizada por 20 minutos com pipeta Pasteur a temperatura ambiente e centrifugada a $10.000 \mathrm{RPM} \mathrm{a} 4^{\circ} \mathrm{C}$, por 30 minutos. 0 sobrenadante teve seu conteúdo protéico quantificado, aliquotado e armazenado a $-20^{\circ} \mathrm{C}$. Para analisar a influência da ação de inibidores de proteases, na qualidade do extrato antigênico, foi realizada extração adicionando os seguintes inibidores ao PBS: PMSF 1mM, leupeptina $1 \mu \mathrm{g} / \mathrm{mL}$, antipaína $1 \mu \mathrm{g} / \mathrm{mL}$ e aprotinina $0,5 \mathrm{TIU} / \mathrm{mL}$.

Métodos sorológicos utilizados. Reação de imunofluorescência indireta, ensaio imunoenzimático (ELISA), Immunoblotting ${ }^{6}$.

Cálculo do limiar de reatividade (cut off). foi determinado utilizando-se a média da leitura de densidade óptica (DO) ou unidades relativas de luminescência (RLU) dos soros de 73 indivíduos controle negativos, acrescida de três desvios padrões.

Dosagem de proteínas. 0 extrato salino de larvas filarióides, 0 extrato antigênico com Zwittergent ${ }^{\circledR}$, com e sem inibidores de proteases, e as amostras da coluna de octyl-sepharose foram quantificadas quanto ao conteúdo de proteína através do kit Micro BCA* Protein Assay Reagent Kit (Pierce).

Caracterização dos extratos antigênicos: eletroforese em gel de poliacrilamida, método de Laemmli (1970). Immunoblotting ${ }^{6}$.

\section{RESULTADOS}

Caracterização dos extratos antigênicos. Análise dos antígenos por SDS-PAGE e immunoblotting: os antígenos SAL, ZWIP e ZW foram analisados por reação de ELISA com pool de soros positivos e negativos para estrongiloidíase humana, obtendo-se reação positiva com diferencial significativo entre eles. A fração F3a foi submetida à purificação por cromatografia de interação hidrofóbica e analisada por CL-ELISA com pool de soros positivos para estrongiloidíase humana.

Os antígenos SAL, ZWIP, ZW e LFS-P foram analisados por SDSPAGE 10\% corado pelo método da prata (Figura 1). Observou-se que os antígenos SAL e o ZWIP apresentaram perfil semelhante, com bandas largas e evidentes de, aproximadamente, 80- e 60-kDa e um screen entre 30- e 10-kDa (canaletas $1 \mathrm{e} 2$, respectivamente). 0 antígeno $\mathrm{ZW}$ apresentou um perfil mais complexo, composto por várias bandas estreitas de alto peso molecular, mas manteve 0 screen encontrado nas outras duas extrações entre 30- e 10-kDa (canaleta 3). Após a purificação o antígeno LFS-P, ao contrário 


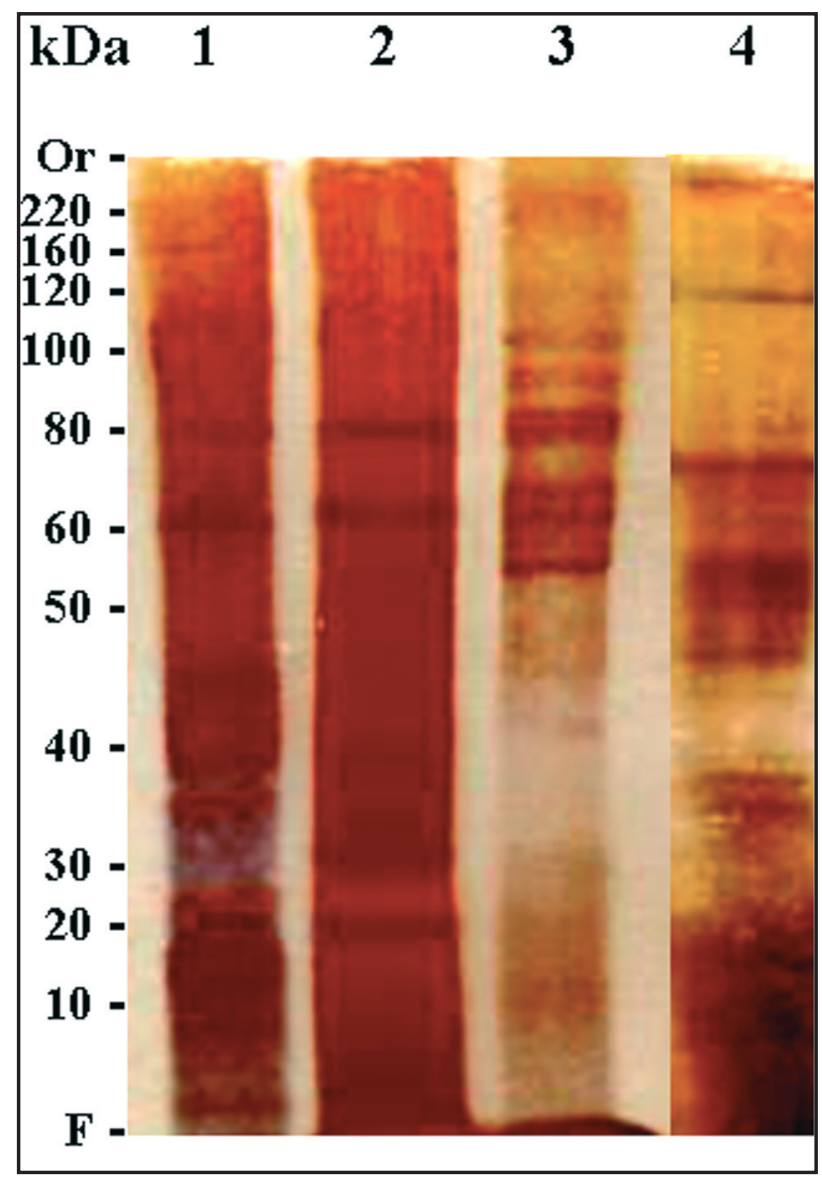

Figura 1 - Perfil em SDS-PAGE/prata da extração salina de larvas filarióides de Strongyloides venezuelensis, 1: da extração antigênica de larvas filarióides de Strongyloides venezuelensis utilizando detergente com e sem inibidores de protease, 2 e 3: respectivamente; antígeno purificado de larvas filarióides de Strongyloides venezuelensis, 4: Or: origem do gel, F: fronte do gel.

dos antígenos SAL e ZWIP, que apresentaram bandas largas em torno de 80 - e $60-\mathrm{kDa}$, mostrou um perfil com várias bandas estreitas localizadas entre 40- e 80-kDa, além de uma banda de aproximadamente 120-kDa, mantendo, também, o screen entre 30- e 10-kDa (canaleta 4).

0 immunoblotting dos diferentes antígenos mostrou forte reatividade na área entre 30- e 10kDa pelo pool de soros positivos (Figura 2), não havendo reconhecimento de nenhuma área quando analisado pelo pool de soros negativos. Apenas o antígeno ZWIP obteve reconhecimento de bandas com peso molecular mais elevado pelos anticorpos.

Proteínas imunodominantes de 41-, 31- e 28-kDa de larvas filarióides de Strongyloides stercoralis foram previamente identificadas como antígenos específicos para o imunodiagnóstico da estrongiloidíase ${ }^{2}$. Este estudo mostra uma parcial caracterização de proteínas de antígeno de larvas filarióides de Strongyloides venezuelensis para identificar melhores extrações antigênicas.

Analisamos quatro diferentes extrações antigênicas a partir de larvas filarióides de Strongyloides venezuelensis tendo encontrado um perfil protéico, através de análise em SDS-PAGE, de bandas evidentes em 80 - e $60-\mathrm{kDa}$ para as preparações SAL

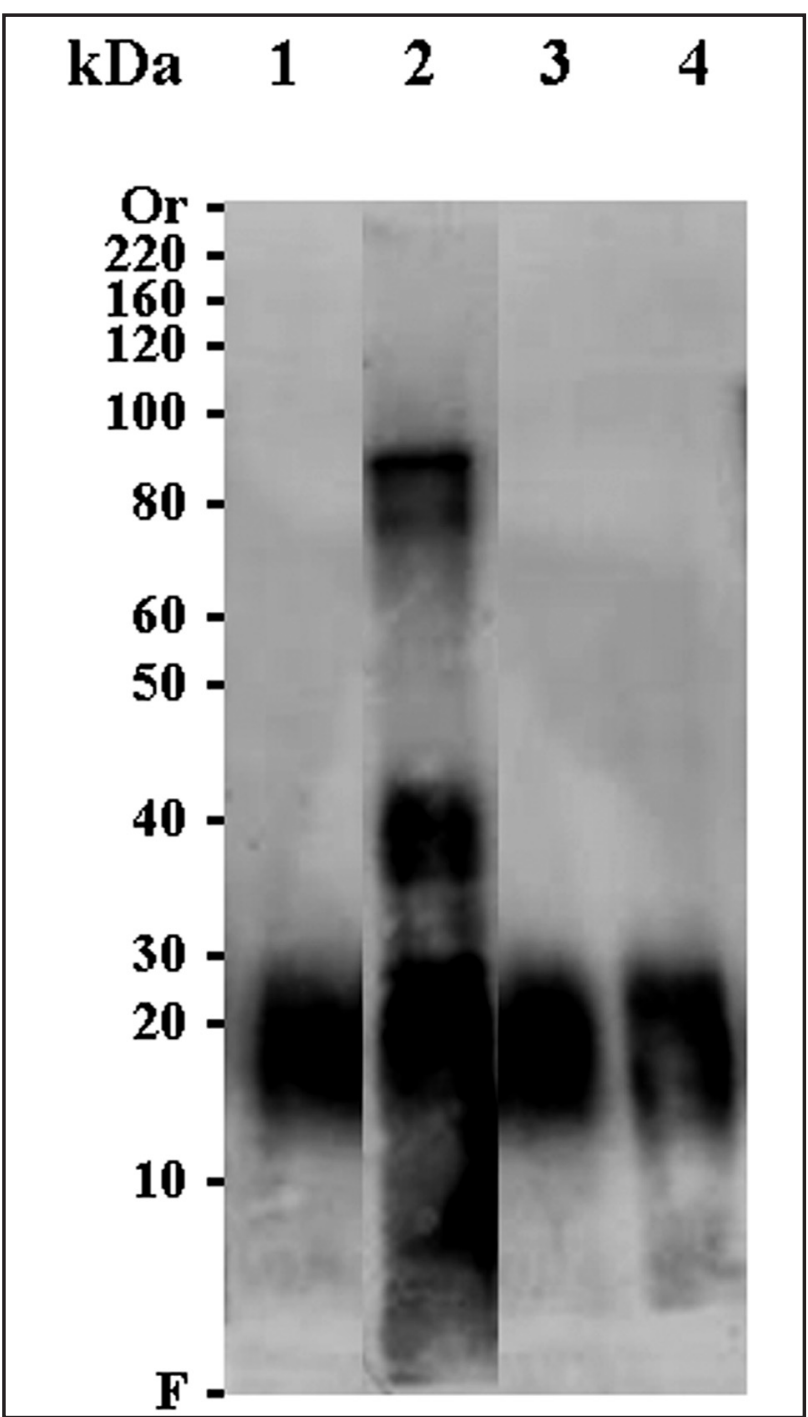

Figura 2 - Immunoblotting da extração salina de larvas filarióides de Strongyloides venezuelensis, 1: da extração antigênica de larvas filarióides de Strongyloides venezuelensis utilizando detergente com e sem inibidores de protease, 2 e 3: respectivamente; antígeno purificado de larvas filarióides de Strongyloides venezuelensis, 4: 0 blot foi incubado com pool de soros positivos para estrongiloidiase humana. Or: origem do gel; F: fronte do gel

e ZWIP, um conjunto de bandas mais finas e peso molecular variando entre 120 - e 50-kDa para $\mathrm{ZW}$ e bandas largas entre 40- e 120-kDa, para o antígeno LFS-P havendo sido observada a presença de um screen protéico entre 30- e 10-kDa para todas as preparações. A localização das proteínas de imunodiagnóstico descritas aqui permanece a ser determinada.

Preparações para reação de imunofluorescência indireta. Fazendo-se a suspensão larval foi possível detectar fluorescência de superfície, porém esta preparação apresentou elevado número de falsos positivos, quando testados os painéis de heterólogos e infecções associadas, o que resultou em uma especificidade muito baixa (<50\%) para esta preparação. Quando feitos os cortes em crio-micrótomo foi possível visualizar fluorescência de superfície e do tubo digestivo (Figura 3).

Análise dos painéis de soros com os diferentes antígenos. Os resultados obtidos pela análise com os antígenos estão representados na Tabela 1 . 
Tabela 1 - Índices de sensibilidade, especificidade, kappa, odds ratio, limiar de reatividade e zona cinza dos painéis de soros analisados pelos testes de ELISA, immunoblotting e imunofluorescência indireta.

\begin{tabular}{|c|c|c|c|c|c|c|c|c|}
\hline \multirow{4}{*}{ Índices } & \multirow{4}{*}{ Número } & \multicolumn{3}{|c|}{ ELISA } & \multicolumn{3}{|c|}{ Immunoblotting } & \multirow{4}{*}{$\begin{array}{c}\text { IFI } \\
\text { Corte em } \\
\text { criomicrótomo }\end{array}$} \\
\hline & & \multicolumn{6}{|c|}{ Antígenos } & \\
\hline & & SAL & ZWIP & $\mathrm{ZW}$ & SAL & ZWIP & $\mathrm{ZW}$ & \\
\hline & & $\%$ & $\%$ & $\%$ & $\%$ & $\%$ & $\%$ & \\
\hline Sensibilidade ${ }^{1}$ & 28 & 89,0 & 85,0 & 57,0 & 100,0 & 100,0 & 96,0 & 75,0 \\
\hline Especificidade $^{2}$ & 73 & 97,0 & 71,0 & 95,0 & 98,0 & 98,0 & 98,0 & 72,0 \\
\hline Especificidade $^{3}$ & 83 & 84,0 & 43,0 & 68,0 & 93,0 & 87,0 & 85,0 & 83,0 \\
\hline Especificidade $^{4}$ & 156 & 90,0 & 60,0 & 81,0 & 96,0 & 92,0 & 91,0 & 82,0 \\
\hline Limiar de reatividade 5 & 184 & 0,358 & 0,109 & 0,223 & 8 & 8 & 8 & $1: 40$ \\
\hline Zona cinza ${ }^{6}$ & 184 & {$[0,393 ; 0,322]$} & {$[0,120 ; 0,098]$} & {$[0,246 ; 0,201]$} & - & - & - & $1: 20$ \\
\hline Índice $K a p p a^{7}$ & 184 & 0,678 & 0,222 & 0,309 & 0,884 & 0,800 & 0,735 & 0,446 \\
\hline Odds ratio $^{7}$ & 184 & 78,33 & 7,97 & 5,839 & “ & “ & 273,85 & 14,330 \\
\hline
\end{tabular}

${ }_{14}^{14}$ Painéis de soros positivos + infecções concomitantes, negativos, heterólogos + infecções associadas e negativos + heterólogos + infecções associadas, respectivamente.

Timiar de reatividade de cada antígeno. ${ }^{6}$ Zona cinza: estabelecida somando-se ou substraindo $10 \%$ no valor do limiar de reatividade. ${ }^{7} 0$ índice kappa e o diagnóstico odds ratio foram calculados nas amostras pertencentes aos painéis de positivos + infecções concomitantes $\left(\mathrm{n}^{\circ}=28\right.$, negativos $\left(\mathrm{n}^{\circ}=73\right)$ e heterólogos + associadas $\left(\mathrm{n}^{\circ}=83\right)$. Intervalos de valores para interpretação do índice kappa: $0,80-1,00=$ excelente; $0,61-0,80=$ bom; $0,41-0,60=$ razoável; menor que $0,40=$ ruim..$^{8} 0$ limiar de reatividade do immunoblotting foi o reconhecimento de bandas entre 30 e 10kDa. ELISA: enzyme-linked immunosorbent assay, IFI: imunofluorescência indireta, SAL: extrato salino de larvas filarióides de Strongyloides venezuelensis, ZWI: extrato de larvas filarióides de Strongyloides venezuelensis em Zwittergent, ZWP: extrato de larvas filarióides de Strongyloides venezuelensis em Zwittergent com inibidor de proteases.
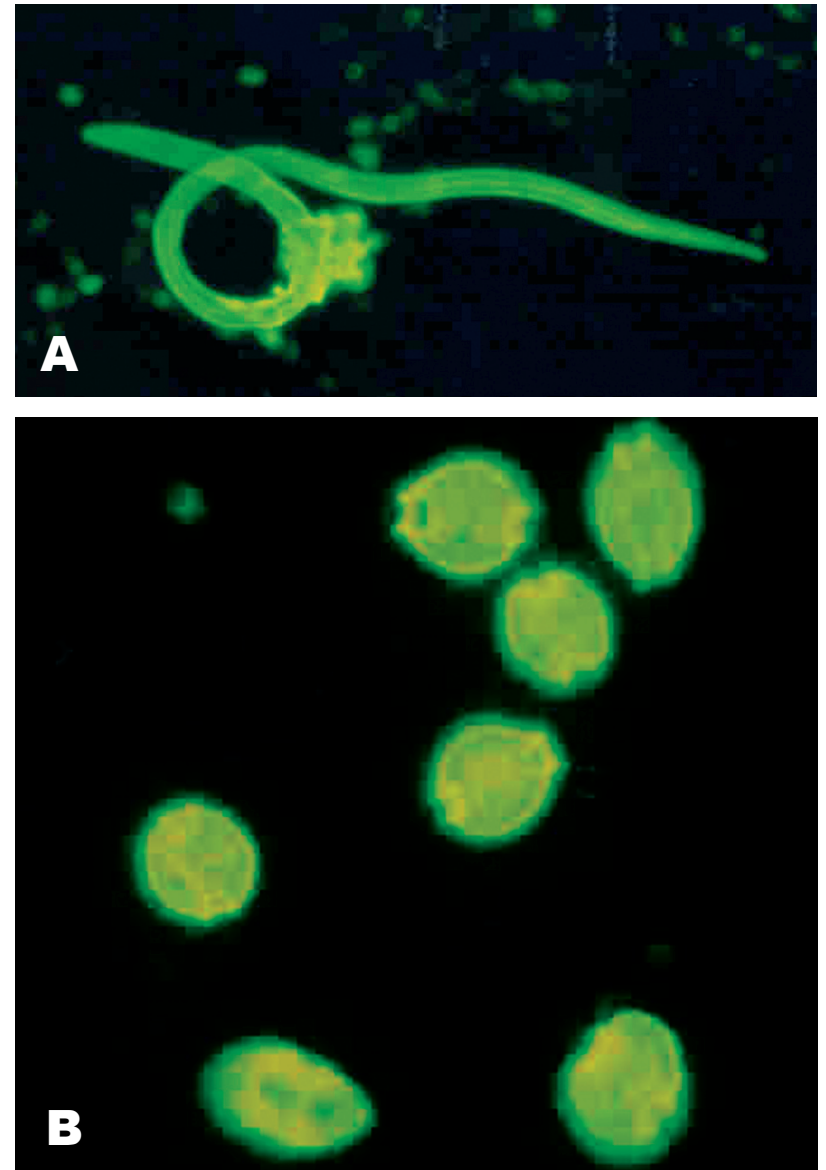

Figura 3A) Suspensão de larvas filarióides de Strongyloides venezuelensis incubada com soro positivo para Strongyloides stercoralis e revelada pelo conjugado antiIgG humana marcada com isotiocianato de fluoresceina, larva em detalhe, para fluorescência de superfície, aumento de 400x. B) Cortes transversais de larvas filarióides de Strongyloides venezuelensis incubadas com soro positivo para Strongyloides stercoralis e reveladas, com o conjugado anti-IgG humana marcada com isotiocianato de fluoresceína. Aumento de 400x.
Análise estatística dos resultados. A extração salina de larvas filarióides de Strongyloides venezuelensis, quando testada pelo ELISA, foi considerada como uma boa metodologia, segundo a análise estatística realizada (índice estatístico kappa), e excelente quando empregado no immunoblotting. Já as extrações utilizando detergente não mostraram bom desempenho para 0 ELISA (Tabela 1).

\section{DISCUSSÃO}

Vários ensaios imunodiagnósticos têm sido estudados para detectar anticorpos contra Strongyloides stercoralis, porém têm se mostrado ineficientes na detecção de infecções disseminadas, além de mostrarem reatividade cruzada nos casos de teníase, filariose e esquistossomose. Entretanto, são importantes para detectar casos de infecções latentes de Strongyloides stercoralis, antes do início da administração quimioterápica ou em pacientes de risco. Portanto, a padronização de um teste específico e sensível, para o diagnóstico da estrongiloidíase humana, ainda, se faz necessária ${ }^{22}$.

Outro possível uso do teste sorológico é a avaliação da eficácia do tratamento, já que, frequientemente, o tratamento com anti-helmínticos não se mostra muito eficaz, e também, devido à dificuldade de confirmação do sucesso do tratamento através de exames parasitológicos ${ }^{20}$.

Quando a composição antigênica dos extratos de verme total de Strongyloides ratti e Strongyloides venezuelensis foi comparada com a de Strongyloides stercoralis foram achadas reações cruzadas com soros dos pacientes, indicando que estas espécies de roedores podem ser utilizadas como fonte de antígenos para o sorodiagnóstico no lugar do antígeno preparado 
a partir de larvas filarióides de Strongyloides stercoralis ${ }^{20}$. A manutenção do ciclo de Strongyloides venezuelensis, que proporciona grande número de larvas filarióides em poucos dias, e a fácil manutenção dos animais em biotérios de pequeno porte, permite que este modelo experimental possa ser mantido nos laboratórios, tornando possível a aplicação dos testes diagnósticos para essa parasitose. Além, de diminuírem o risco de contaminação dos técnicos envolvidos, por se tratar de uma espécie parasito específico de roedores ${ }^{81} 20$.

0 reconhecimento específico, das bandas entre 30- e 10$\mathrm{kDa}$, pela IgG sérica de pacientes verdadeiramente positivos para estrongiloidíase e o não reconhecimento de qualquer banda para os verdadeiramente negativos, como um critério para 0 imunodiagnóstico, proporcionou elevados índices de sensibilidade (SAL - 100/ZWIP - 100\%/ ZW - 96\%) e especificidade (SAL-96\%/ ZWIP-92\%/ZW-91\%) para todas as amostras analisadas (Tabela 1). Esses índices foram mais elevados do que os encontrados pelo ELISA (sensibilidade de $89 \%, 85 \%$ e $57 \%$; especificidade de $84 \%$, 43\% e $68 \%$ para SAL, ZWIP e ZW, respectivamente).

0 reconhecimento de bandas com peso molecular mais elevado, pelo painel de positivos, apenas para o antígeno ZWIP, pode ser explicado pelo uso de inibidores de proteases durante a extração, estas proteínas, também, podem ser responsáveis pelas reações cruzadas encontradas, para este antígeno, quando analisado o painel de soros heterólogos.

A amostra detectada como positiva em todas as extrações antigênicas, tanto pelo ELISA como pelo immunoblotting, dentro do painel de negativos, pode estar representando um caso de estrongiloidíase oculta. Os demais casos de reações inespecíficas observados, principalmente no grupo de heterólogos, podem estar indicando reatividade cruzada do antígeno de Strongyloides com outros parasitas, já que com o emprego do immunoblotting o número de casos encontrados é bastante reduzido.

As proteínas imunodominantes de Strongyloides stercoralis são detectáveis em extratos antigênicos salinos, assim como, em detergente. Esses epítopos parecem ser específicos para Strongyloides stercoralis pois não se apresentam em extratos de Strongyloides cebus e Strongyloides ratti, parasitas de primatas e roedores, respectivamente 21

Ambas as extrações, em solução salina ou detergente, de larvas filarióides de Strongyloides venezuelensis, mostraram solubilidade e presença de elevada dosagem protéica, quando utilizado o processo de homogeneização manual e sonicação (SAL $134 \rho g / \mu \mathrm{L}, \mathrm{ZWIP} 145 \rho g / \mu \mathrm{L}$ e ZW $132 \rho g / \mu \mathrm{L}$ ), porém os extratos em detergente revelaram menor especificidade quando comparados ao extrato salino.

Apesar da elevada especificidade e sensibilidade encontradas para o immunoblotting quando comparadas com o ELISA, a reação de immunoblotting não é recomendável para o uso na rotina de laboratórios, por requerer um prazo maior para liberação dos resultados, mas é possivel de ser implantada como um teste confirmatório, devendo ser avaliado em diferentes situações clínicas.

A extração butanólica de proteínas glicoconjugadas e sua posterior purificação em coluna de afinidade hidrofóbica vêm sendo estudadas para obtenção de antígenos purificados e, portanto mais específicos, para o diagnóstico de outras parasitoses ${ }^{1}$ Pesquisas recentes, também, vêm sendo realizadas na tentativa de introduzir ensaios quimioluminescentes como método para detecção de reagentes. Estes ensaios têm se revelado altamente sensíveis, de fácil execução e não utilizam radioisótopos em sua preparação, o que os torna uma boa alternativa para melhorar o diagnóstico sorológico de infecções parasitárias, embora ainda não tenham sido empregados na rotina ${ }^{47} 23$.

0 perfil encontrado, através de análise por SDS-PAGE, indica a presença de glicoconjugados imunoreagentes nas extrações antigênicas de larvas filarióides de Strongyloides venezuelensis (Figuras 1 e 2, canaletas 1, 2 e 3). Realizando o procedimento de extração e purificação por cromatografia de interação hidrofóbica, obtivemos um antígeno purificado com estas proteínas glicoconjugadas (Figuras 1 e 2, canaleta 4). A reação de imunofluorescência utilizando como antígeno cortes em criomicrótomo de larvas L3, aparentemente pode ser empregada como técnica auxiliar para o diagnóstico da estrongiloidíase, devido aos bons índices de sensibilidade (75\%) e especificidade (82\%) encontrados nessa pesquisa, porém aconselha-se, que esta metodologia seja empregada em associação a outra, como por exemplo, ELISA para aumentar o grau de sensibilidade.

0 sorodiagnóstico é um avanço importante para o diagnóstico de parasitoses, principalmente para indivíduos imunossuprimidos, onde esta doença pode diminuir a qualidade e a sobrevida desses pacientes. Assim, o ELISA e a imunofluorescência podem ser uma importante ferramenta para o diagnóstico da estrongiloidíase, tanto em diagnósticos individuais como em inquéritos epidemiológicos, sendo testes rápidose mais baratos. A reação de immunoblotting pode ser uma importante ferramenta para confirmar resultados duvidosos encontrados.

\section{AGRADECIMENTOS}

Aos Drs. Júlia Maria Costa-Cruz e Marcelo Simão Ferreira, do laboratório de Parasitologia da Universidade Federal de Uberlândia, por terem cedido amostras de soros de indivíduos portadores de estrongiloidíase humana. Ao Prof. Dr. Igor Correia de Almeida, do Laboratório de Glicobiologia de Parasitas do ICB, pelas sugestões para o aperfeiçoamento desta pesquisa.

\section{REFERÊNCIAS}

1. Almeida IC, Krautz GM, Krettli AU, Travassos LR Glycoconjugates of Trypanosoma cruzi: a $74 \mathrm{kD}$ antigen of trypomastigotes specifically reacts with lytic anti-alphagalactosyl antibodies from patients with chronic Chagas disease. Journal of Clinical Laboratory Analysis 7: 307-316, 1993.

2. Conway DJ, Bailey JW, Lindo, JF, Robinson RD, Bundy DA, Bianco AE. Serum IgG reactivity with 41-, 31-, and 28-kDa larval proteins of Strongyloides stercoralis in individuals with strongyloidiasis. The Journal of Infectious Diseases 168: 784-787, 1993.

3. Costa-Cruz JM, Bullamah CB, Gonçalves-Pires MR, Campos DM, Vieira MA. Cryo-Microtome Sections of Coproculture Larvae of Strongyloides stercoralis and Strongyloides ratti as Antigen Sources for the Immunodiagnosis of Human Strongyloidiasis. Revista do Instituto de Medicina Tropical de São Paulo 39: 313-317, 1997. 
4. Doll NJ, Wilson MR, Salvaggio JE. Inhibition of polymorphonuclear leukocyte chemiluminescence for detection of immune complexes in human sera. The Journal of Clinical Investigation 66: 457-464, 1980.

5. Faust EC, D'antoni JS, Odom V. A Critical Study of Clinical Laboratory Technics for the Diagnosis of Protozoan Cysts and Helminth Eggs in Feces. I - Preliminary Communication. American Journal of Tropical Medicine 18: 169-183, 1938.

6. Ferreira AW, Ávila SLM. Diagnóstico Laboratorial das Principais Doenças Infecciosas e Auto-Imunes. 1ª edição, Editora Guanabara-Koogan, 1-6, 1996.

7. Gridley DS, Lau BH, Tosk JM. Phagocytic cell chemiluminescence using different zymosan preparations. Jornal of Clinical Laboratory Analyses 5: 101-105, 1991.

8. Grove DI, Blair J. Diagnosis of Human Strongyloidiasis by Immunofluorescence, Using Strongyloides ratti and $S$. stercoralis Larvae. American Journal of Tropical Medicine 30: 344-349, 1981

9. Hoffman WA, Pons JA, Janer JL. The Sedimentation-Concentration Method in Schistosomiasis mansoni. Puerto Rico Journal of Public Health 9: 281-298, 1934.

10. Machado ER, Faccioli LH, Costa Cruz JM, Lourenço EV, Roque-Barreira MC, Gonçalves-Pires MRF, Ueta MT. Strongyloides venezuelensis: the antigenic identity of eight strains for the immunodiagnosis of human strongyloidiasis. Experimental Parasitology $119: 7-14,2008$.

11. Machado ER, Ueta MT, Gonçalves-Pires MRF, Oliveira JB, Faccioli LH, Costa-Cruz JM. Diagnosis of Human Strongyloidiasis Using Particulate Antigen of Two Strains of Strongyloides venezuelensis in Indirect Immunofluorescence Antibody Test. Experimental Parasitology 99: 52-55, 2001.

12. Northern C, Grove D. Strongyloides stercoralis: antigenic analysis of infective larvae and adult worms. International Journal for Parasitology 20: 381-387, 1990.

13. Nozais JP, Thellier M, Datry A, Danis M. Disseminated Strongyloidiasis. Presse. Medicale 30: 813-818, 2001.

14. Paula FM,Castro E, Gonçalves-Pires MRF, Marçal MG, Campos DM, Costa-Cruz JM. Parasitological and immunological diagnoses of
Strongyloidiasis in immunocompromised and non- immunocompromised children at Uberlandia, State of Minas Gerais, Brazil. Revista do Instituto de Medicina Tropical de São Paulo 42: 51-55, 2000.

15. Ravi V, Ramachandran S, Thompson RW, Andersen JF, Neva FA. Characterization of a recombinant immunodiagnostic antigen (NIE) from Strongyloides stercoralis L3-stage larvae. Molecular and biochemical Parasitology 125: 73-81, 2002.

16. Rossi CL, Takahashi EEH, Teixeira AL, Barros-Mazon S, Trevisan RC. Avaliação de Preparações Antigênicas de Strongyloides stercoralis para o Imunodiagnóstico da Estrongiloidíase. Revista da Sociedade Brasileira de Medicina Tropical 26: 83-87, 1993.

17. Rugai E, Mattos T, Brisola AP. Nova técnica para isolar larvas de nematóides das fezes: modificação do método de Baermann. Revista do Instituto Adolfo Lutz, 14: 1-8, 1954.

18. Sanchez PR, Guzman AP, Guillen SM, Adell RI, Estruch AM, Gonzalo IN, Olmos CR. Endemic Strongyloidiasis on the Spanish Mediterranean Coast. The Quarterly Journal of Medicine 94: 357-363, 2001.

19. Sarangarajan R, Ranganathan A, Belmonte AH, Tchertkoff V. Strongyloides stercoralis infection in AIDS. AIDS Patient Care STDS 11: 407-414, 1997.

20. Sato Y, Inoue F, Kiyuna S, Matsuyama R, Shiroma Y. Immunoblot analysis of three antigen preparations from Strongyloides stercoralis larvae in human strongyloidiasis. Transactions of the Royal Society of Tropical Medicine and Hygiene 84: 403-406, 1990.

21. Sato Y, Takara M, Otsuru M. Detection of antibodies in strongyloidiasis by enzyme-linked immunosorbent assay (ELISA). Transactions of the Royal Society of Tropical Medicine and Hygiene 79: 51-55, 1985

22. Siddiqui AA, Berk SL. Diagnosis os Strongyloides stercoralis infection. Clinical Infectious Diseases 33: 1040-1047, 2001.

23. Starkebaum G, Stevens DL, Henry C, Gavin SE. Stimulation of human neutrophil chemiluminescence by soluble immune complexes and antibodies to neutrophils. Journal of Laboratory and Clinical Medicine 98: 280-291, 1981. 